\title{
Anatomical variations in the origin of profunda femoris artery
}

\author{
Preeti Shrivastava
}

Department of Anatomy, North Delhi M unicipal Corporation Medical College and Hindu Rao Hospital, Malkaganj, Delhi. INDIA. Email: drpreetishrivastava@gmail.com

Abstract The profunda femoris artery (PFA) generally arises from the lateral aspect of femoral artery (FA) in the thigh, $3.5 \mathrm{~cm}$ distal to the inguinal ligament. Variations with respect to its point of origin, relation and branching pattern have been widely reported. Dissection of 21 lower limbs in the department of Anatomy at North Delhi Municipal Corporation Medical College and Hindu Rao Hospital, Delhi, demonstrated variations in the origin of PFA from the femoral artery. The PFAs were examined in detail for their origin, branches and relations. The distance of origin of PFA keeping midpoint of inguinal ligament as a reference point, were noted. PFA was found to originate from the femoral artery in $95.24 \%$ cases ( 20 out of 21 lower limbs) at a mean distance of $3.16 \mathrm{~cm}$ on the right side and $3.07 \mathrm{~cm}$ on the left side. In one rare case the PFA was found to originate $1.5 \mathrm{~cm}$ above the midpoint of inguinal ligament from the lateral aspect of external iliac artery at the pelvic brim. Knowledge of this high origin of PFA has clinical implications for revascularizing by-pass surgeries such as aorto-common femoral artery bypass and profundoplasty, performed to relieve limb ischemia in atherosclerotic occlusive disease of aorto-iliac segment and superficial femoral artery, as well as in true aneurysms of common iliac artery and PFA.

Key Word:

Address for Correspondence:

Dr. Preeti Shrivastava, Department of Anatomy, North Delhi Municipal Corporation Medical College and Hindu Rao Hospital, Malkaganj, Delhi. INDIA.

Email: drpreetishrivastava@ gmail.com

Received Date: 18/02/2018 Revised Date: 13/03/2018

DOI: https://doi.org/10.26611/1001611

\begin{tabular}{|l|l|}
\hline \multicolumn{2}{|c|}{ Access this article online } \\
\hline Quick Response Code: & Website: \\
www.medpulse.in \\
\hline
\end{tabular}

\section{INTRODUCTION}

The profunda femoris artery (PFA) generally arises from the lateral aspect of femoral artery (FA) in the thigh. However, there are reports of its origin from medial or posterior side of femoral artery. Its origin is commonly $3.5 \mathrm{~cm}$ distal to the inguinal ligament. It mainly supplies flexors, adductors and extensors of thigh. PFA forms anastomosing networks above with the branches of internal and external iliac arteries and below with popliteal artery. Variations with respect to its point of origin, relation and branching pattern have been widely reported.

\section{MATERIALS AND METHODS}

Dissection of 21 lower limbs in the department of Anatomy at North Delhi Municipal Corporation Medical College and Hindu Rao Hospital, Delhi, demonstrated variations in the origin of PFA from the femoral artery. The PFAs were examined in detail for their origin and relations. The distance of origin of PFA keeping midpoint of inguinal ligamentas a reference point, were noted. Appropriate photographs were taken and relevant measurements recorded with reference to the midpoint of inguinal ligament.

\section{RESULTS}

In the present study, it was found that PFA commonly $(95.24 \%)$ arises from femoral artery (FA), except in one case $(4.76 \%)$ where PFA was found to arise from external iliac artery, which is a rare variant. This study also shows that PFA mostly arises independently $(71.42 \%)$ from FA. Only in $23.8 \%$ cases did PFA arise along with lateral 
circumflex femoral artery (LCFA) or medial circumflex femoral artery (MCFA) or with both by a common trunk. PFA originates independently from FA in $70 \%$ of the right lower limbs andin $72.72 \%$ of the left lower limbs. For $30 \%$ of the right lower limbs and $18.8 \%$ of the left lower limbs, PFA originated from FA as a common trunk with LCFA and/or MCFA. However, PFA originated from external iliac artery in one case $(9.09 \%)$ of left lower limb. No case was reported from the right lower limb. This finding is the major contribution of the study. The PFA originates from lateral (14.29\%), posterior $(47.62 \%)$ or posterolateral $(38.1 \%)$ aspectof the right and left FA. The PFA originated from the lateral side of FA in $20 \%$ of right lower limbs and $9.09 \%$ of left lower limbs. Similarly PFA arises more commonly from the posterior aspect in the left lower limb (54.54\%) than the right lower limb (40\%). But the origin of PFA from the posterolateral aspect is more common on the right side (40\%) than the left side $(36.36 \%)$. None of the limbs showed a medial or posteromedial origin of PFA from the FA. The probability of finding PFA originating from posterior or posterolateral aspect of FA to be same ( $40 \%$ each) in the right lower limb; while the probability of PFA originating from posterior is higher $(54.54 \%)$ than posterolateral $(36.36 \%)$ aspects of FA in left lower limbs. These findings are reported in a tabular form in table 1 . The mean distance of origin of PFA from midpoint of inguinal ligamentwas calculated from table 2 as $3.16 \mathrm{~cm}$ for the right lower limbs and $3.07 \mathrm{~cm}$ for the left lower limbs. A major contribution of this study is the reporting of one PFA originating from external iliac artery as shown in figure 1. Moreover, this was found to originate $1.5 \mathrm{~cm}$ above the midpoint of inguinal ligament from the lateral aspect of external iliac artery at the pelvic brim (figure 1) and it was located medial to psoas tendon, lateral to femoral artery and anterior to the pectineus muscle. The inferior epigastric and deep circumflex iliac arteries were observed to arise high up from the external iliac artery near the mid-pelvic brim, $4 \mathrm{~cm}$ proximal to the inguinal ligament (figure 1). The lateral and medial circumflex branches of left sideoriginated in the thigh, 1.5 and $2.5 \mathrm{cms}$ distal to the inguinal ligament, respectively (figure 2). The left LCFA was coursing deep to femoral nerve, located on its lateral aspect (figure 2). The leftFA crossed the femoral vein anteriorly, near the base of the femoral triangle. This crossing was also $7 \mathrm{~cm}$ distal to the midpoint of inguinal ligament (figure 2).

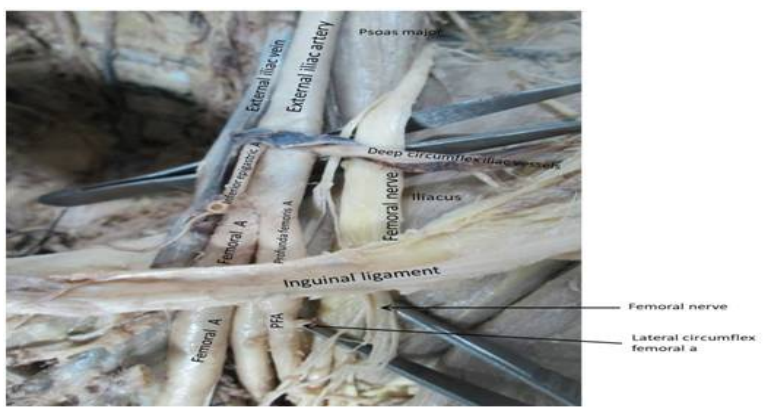

Figure 1

Photograph shows:

1. High origin of the PFA from the external iliac artery inthe pelvis on the left side, $1.5 \mathrm{~cm}$ proximal to themidpoint of inguinal ligament.

2. High origin of inferior epigastric and deep circumflexiliac arteries from the left external iliac artery at the mid-pelvic brim, $4 \mathrm{~cm}$ proximal to the inguinal ligament

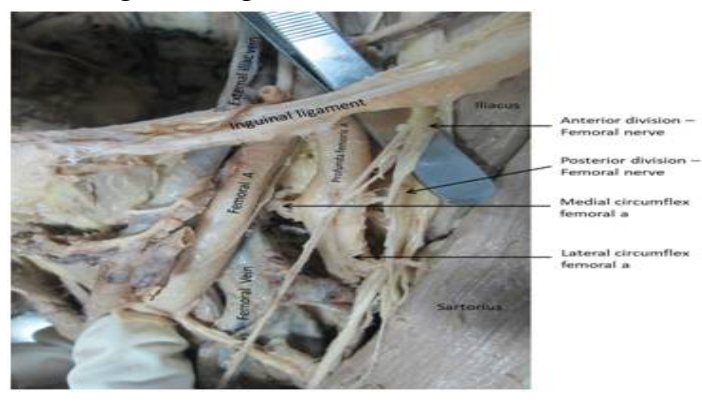

Figure 2

Photograph shows the high origin of the LCFA and MCFA arteries from PFA, in the left thigh. Note the:

i) LCFA passes deep to both the divisions of femoral nerve and

ii) FA crosses the femoral vein closer to the inguinal ligament $(7 \mathrm{~cm})$.

Table1: Site and Source of origin of PFA and its mean distance.

\begin{tabular}{|c|c|c|c|c|c|c|}
\hline & \multicolumn{3}{|c|}{ Right lower limbs (10 in number) } & \multicolumn{3}{|c|}{ Left lower limbs (11 in number) } \\
\hline \multirow{6}{*}{ Site of origin of PFA } & Lateral & 2 & $20 \%$ & Lateral & 1 & $9.09 \%$ \\
\hline & Posterior & 4 & $40 \%$ & Posterior & 6 & $54.54 \%$ \\
\hline & Posterolateral & 4 & $40 \%$ & Posterolateral & 4 & $36.36 \%$ \\
\hline & \multicolumn{4}{|c|}{ Total Lateral origin } & 3 & $14.29 \%$ \\
\hline & \multicolumn{4}{|c|}{ Total Posterior origin } & 10 & $47.62 \%$ \\
\hline & \multicolumn{4}{|c|}{ Total Posterolateral origin } & 8 & $38.1 \%$ \\
\hline Source of origin of & Independent origin of PFA & 7 & $70 \%$ & Independent origin of PFA & 8 & $72.72 \%$ \\
\hline
\end{tabular}




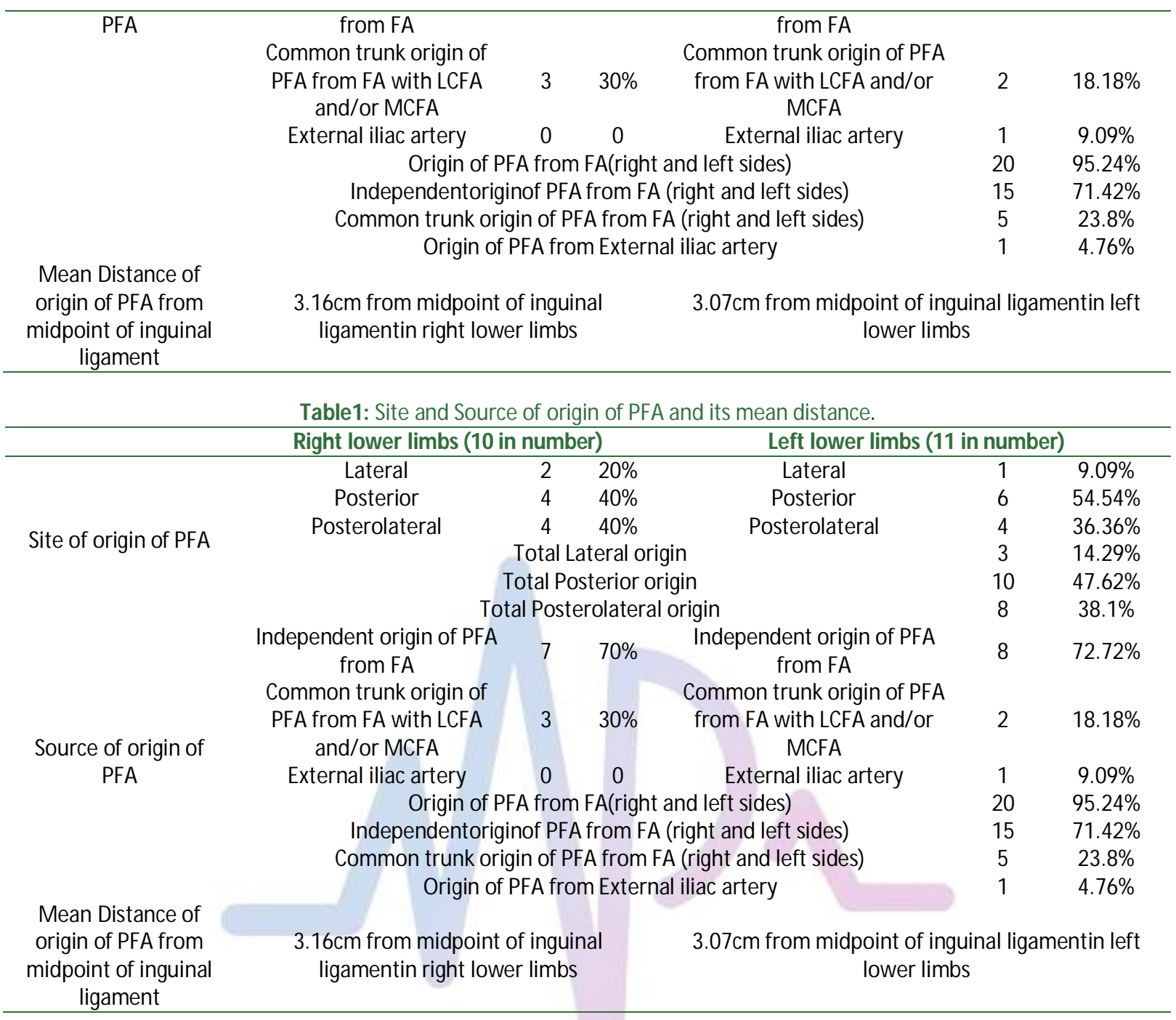

\section{DISCUSSION}

The mean distance of origin of the PFA from the midpoint of inguinal ligament on the right side was $3.16 \mathrm{~cm}$ and on the left side was $3.07 \mathrm{~cm}$, indicates that the origin of the right PFA is usually distal to the origin of the left PFA by $0.09 \mathrm{~cm}$, which is less than the study by Bannister et al. and Manjappa et al, and is also less than the average distance of origin reported by Snell $4 \mathrm{~cm}$, Siddharth et al. $4.4 \mathrm{~cm}$, and Dixit et al. $4.75 \mathrm{~cm}^{7,9,16}$, ${ }^{17,18}$. Review of literature shows that high origin of PFA mostly occurs near the inguinal ligament ${ }^{1,2,3,4,5,6,7,8,9,10,11}$. The present study appears to be the first report to demonstrate the unilateral pelvic origin of PFA from the left external iliac artery, $1.5 \mathrm{~cm}$ above the midpoint of inguinal ligament. This high origin of PFA has clinical implications while performing revascularization by-pass surgeries such as aorto-common femoral artery bypass ${ }^{12}$ and profundoplasty ${ }^{13}$, to relieve limb ischemia in atherosclerotic occlusive disease of aorto-iliac segmentand superficial femoral artery, as well as in true aneurysms of common iliac artery and PFA ${ }^{14}$. Itmay form a site for false aneurysms after trauma following intra-arterial procedures and may become a difficult access site for dilatation in stenotic lesions near its origin $^{15}$.

\section{CONCLUSION}

The origin of the PFA from the midpoint of inguinal ligament is placed more proximally than in other studies. However, the right PFA originates more distally than left in most cases. It is also important to bear in mind the lateral relation of femoral nerve, which can help prevent nerve damage or compression. The present report highlights a rare and unique unilateral pelvic origin of PFA.Precise knowledge of the anatomy and awareness of variations of the origin and location of PFA is crucial for surgeons. 


\section{REFERENCES}

1. Tomaszewski KA, Henry BM, Vikse J et al 2017 Jan. Variations in the origin of the deep femoral artery: A meta-analysis. ClinAnatEpub 2016 Feb 2; 30(1):106-113. doi: 10.1002/ca.22691..

2. Bandyopadhyay M, Biswas S, Roy R. Vessels in femoral triangle in a rare relationship. Singapore Med J 2010 Jan; 51(1):e3-5.

3. Rusu MC, Ilie AC, Brezean I. Human anatomic variations: common, external iliac, origin of the obturator, inferior epigastric and medial circumflex femoral arteries, and deep femoral artery course on the medial side of the femoral vessels. SurgRadiolAnat2017 Apr 27. Doi; 10.1007/s00276-017-1863-6.

4. Nasr AY,Badawoud MH, Al-Hayani AA, Hussein AM Origin of profunda femoris artery and its circumflex femoral branches: anatomical variations and clinical significance. Folia Morphol (Warsz) 2014 Feb; 73(1):5867. doi: 10.5603/FM.2014.0008.

5. Prakash, Kumari J, Kumar Bhardwaj A, Jose BA, Kumar Yadav S, Singh G. Variations in the origins of the profunda femoris, medial and lateral femoral circumflex arteries: a cadaver study in the Indian population. Rom J MorpholEmbryol2010; 51(1):167-70.

6. Perera J. Anatomy of the origin of the deep femoral artery. Ceylon Med J 1995 Dec; 40(4):139-41.

7. Siddharth P, Smith NL, Mason RA, Giron F. Variational anatomy of the deep femoral artery. Anat Rec 1985 Jun; 212(2):206-9.

8. Baliyan R, Arora J, Gupta V et al. Anomalous disposition of profunda femoris artery: a clinicoanatomical appraisal.Clin Ter. 2011; 162(5):435-7.

9. Manjappa T, Prasanna LC. Anatomical variations of the profunda femoris artery and its branches-a cadaveric study in South Indian population. Indian J Surg 2014 Aug;76(4):288-92. doi: 10.1007/s12262-012-06773.Epub 2012 Jul 25.
10. Goel S, Arora J, Mehta V, Sharma M, Suri RK, Rath G. Unusual disposition of lateral circumflex femoral artery: Anatomical description and clinical implications. World $\mathbf{J}$ Clin Cases. 2015 Jan 16;3(1):85-8. doi: 10.12998/wjcc.v3.i1.85.

11. Choy KW, Kogilavani S, Norshalizah $\mathrm{M}$ et al. Topographical anatomy of the profunda femoris artery and the femoral nerve: normal and abnormal relationships. Clin Ter 2013; 164(1):17-9. doi: 10.7417/T.2013.1504.

12. Prendiville EJ1, Burke PE, Colgan MP, Wee BL, Moore DJ, Shanik DG. The profunda femoris: a durable outflow vessel in aortofemoral surgery.J Vasc Surg. 1992 Jul; $16(1): 23-9$.

13. Khwaja HA1, Omotoso PO. Bifurcated Dacron patch for simultaneous superficial femoroplasty and profundoplasty: a case report. J Med Case Rep. 2009 Nov; 24; 3: 9294.

14. Milotic F1, Milotic I, Flis V Isolated atherosclerotic aneurysm of the profunda femoris artery. Ann Vasc Surg. 2010 May; 24(4):552.e1-3. doi: 10.1016/j.avsg.2009.09.014. Epub 2010 Feb 7.

15. Defraigne JO1, Vasquez C, Limet R. Ruptured aneurysm of the profunda femoral artery associated with polyaneurysmal disease. ActaChir Belg. 1997 Apr; 97(2):93-6.

16. Bergman RA, Thompson SA, Afifi AK, Saadeh FA. Compendium of human anatomic variation: text, atlas, and world literature. Baltimore: Urban and Schwarzenberg; 1988; 86-87.

17. Bannister LH, Berry MM, Collins P.Cordiovascular system. In: Gray's anatomy: anatomical basis of medicine and surgery, 38th edn. Churchill Livingstone, London, 1995; 1566-1568.

18. Dixit DP, Mehta LA, Kothari ML. Variations in the origin and course of profunda femoris. J AnatSoc India. 2001; 50(1):6-7.

Source of Support: None Declared
Conflict of Interest: None Declared

